\title{
The Associations of Reactive Oxygen Metabolites and Biological Antioxidant Potentials with Related Factors in Healthy Youth
}

\author{
Kazuyoshi Tamae ${ }^{1 *}$, Kazuhiro Aoki ${ }^{2}$, Shingo Nakamaru' ${ }^{2}$, Kazunori Koshikawa ${ }^{2}$, Kazuhiko Sakuma ${ }^{2}$, and Takeshi Hirano ${ }^{3}$ \\ ${ }^{1}$ Faculty of Education, Oita University, Oita City, Oita, 870-1192, Japan \\ ${ }^{2}$ Faculty of Health and Sports Science, Juntendo University, Inzai City, Chiba, 270-1695, Japan \\ 3Faculty of Family and Consumer Science, Kamakura Women's University, Kamakura City, Kanagawa, 247-0056, Japan
}

${ }^{*}$ Correspondence author: Kazuyoshi Tamae, Faculty of Education, Oita University, Oita City, Oita, 870-1192, Japan; Tel: +81975547624, Fax: +81975547624; E-mail: k-tamae@oita-u.ac.jp

Received: August 07, 2019; Accepted: August 15, 2019; Published: August 26, 2019;

\begin{abstract}
To investigate the statuses of the relationships between exercise, dietary habits, sleep, and serum biomarkers, such as reactive oxygen metabolites (ROM) and biological antioxidant potentials (BAP), we conducted a questionnaire survey and collected urine and blood samples from high school students and university athletes. Using the ROM and BAP values, the Oxidative stress-Antioxidant capacity Ratio (OAR) which reflects the antioxidant capability was calculated. Although differences among the subgroups, such as gender, schools, and exercise habits etc., were observed, the levels of both ROM and BAP were low, reflecting good psychosomatic statuses. The significant positive association between these two markers was indicated. The univariate analysis indicated that the ROM value was significantly inversely associated with the consumption of 'pork', 'chicken', and 'beef', while the OAR correlations to these three foods were significantly positive. The multivariate analysis revealed that 'female' as compared with 'male' had a significantly increased ROM level, whereas 'soybean' $(\mathrm{P}<0.001)$ decreased it. Similarly, the BAP levels of 'female' and 'soybean' were significant decreased. In addition, in terms of OAR, 'soybean' was significantly increased, while 'female' was significantly decreased. The present findings should be considered in the future through carefully designed epidemiological studies. In particular, comparisons between the present results and those obtained from another population sample, such as elderly citizens, should be considered.
\end{abstract}

Keywords: Adolescents, Biological Antioxidant Potentials, Lifestyle, Reactive Oxygen Metabolites

\section{Introduction}

As accumulating evidence has indicated, oxidative stress is caused by an imbalance between oxidants and antioxidants [1]. Increased oxidative stress plays an important role in the progression of chronic diseases, and aging. As reported in previous studies [2, 3], strong links have been found between oxidative stress and various factors, such as cigarette smoking, alcohol drinking, and aging. Therefore, measuring oxidative stress levels may be useful not only for the prediction of chronic disease propensity, but also for early health promotion and administration. Particularly, from the viewpoint of health promotion, studies using biomarkers for children and infants should be performed, to accumulate beneficial evidence for individual and group health promotion. In infants, measuring oxidative stress or antioxidant capacity was conducted not only in unhealthy subjects with diabetes [4-6], hypercholesterolemia [7], atopic dermatitis [8], and Helicobacter pylori infection [9], but also in healthy subjects [1014]. However, almost all of these findings [4-13] were based on small groups. Investigations using biomarkers based on epidemiological concepts among larger groups of infants are required.

The BAP and ROM tests have been developed for measuring reactive oxygen metabolites (ROM) and biological antioxidant potentials (BAP) in blood. The main component of ROM is hydroperoxide $[15,16]$, which causes cell death and tissue damage $[17,18]$. In spite of its oxidant power, the hydroperoxide level in blood can be determined accurately, and it is comparatively stable in comparison with the parent free radicals [19]. The BAP test measures the capacity of blood to convert an $\mathrm{Fe} 3+$ reagent to $\mathrm{Fe} 2+[20,21]$. These tests are conducted using the Free Radical Analytical System 4 (FRAS4; Diacron, Grosseto, Italy) [15, 16, 22]. Although the amount of time required to test both ROM and BAP is remarkably shorter (approximately $15 \mathrm{~min} / \mathrm{sample}$ ), as compared with other serum oxidative markers, these ROM and BAP tests are reportedly sensitive [20]. Several studies about the ROM and BAP tests for adults [15-20] have been conducted.

However, as far as we know, little is also known about the levels of ROM and BAP in youths or adolescents, or about related factors. Therefore, further investigations using ROM and BAP are necessary for a comparatively large sample of infants, to consider whether these two markers reflect the actual statuses of the oxidative stress level and the antioxidant capacity, or how these are influenced by related factors. Consequently, we collected blood from healthy young students and asked them to complete a questionnaire survey, to consider the actual 
statuses of oxidative stress and antioxidant capacity by means of measuring the ROM and BAP values, and related factors. Essentially, the purposes of the present study are to consider (1) the levels of ROM and BAP among adolescents and youths, (2) the differences in the ROM and BAP levels among subgroups with different characteristics, and (3) the relationships of ROM and BAP with various related factors.

\section{Material and Methods}

\section{Ethical procedure, blood collection and questionnaire survey}

In this study, 329 high school students (193 males and 136 females) and 41 university students ( 33 males and 8 females) participated (total 370 subjects). The university students are members of a track and field athletics club, and they train in either sprint or jump events almost daily. Incidentally, the present university students include candidates for the next Olympic Games. The 329 high school students were classified according to whether or not the students participate in an extra-curricular sports activity, and we decided on the following three subgroups: ordinary high school students group (OS: 50 males and 63 females), high school athletes group (HA: 143 males and 73 females), and university athletes group (UA: 33 males and 8 females) (Table1).

The study protocol was approved by the Ethics Committee of the Faculty of Education and Culture, University of Miyazaki (No. 001), along with the Declaration of Helsinki (Edinburgh, October 2000). The participants provided written informed consent before the study. All subjects were in good health status at the time of blood collection. Venous blood samples (approximately $7 \mathrm{cc}$ ) were collected from participants through venipuncture of the median cubital vein, by an experienced physician and registered nurses. At the same time, each individual's information on school, age, sex, height, weight (for $\mathrm{BMI}$ ), and lifestyle was obtained from the questionnaire. With regard to lifestyle items, self-estimations of exercise and dietary habits were expressed on a three point scale as follows: "not or rarely", "moderately", "almost regularly".

\section{Measurements of ROM and BAP}

To estimate the levels of both oxidative stress and antioxidant capacity, the ROM and BAP tests using the FRAS4 were conducted. In general, a venous blood sample from the fingertip is utilized for the ROM and BAP tests by using FRAS4. However, a blood sample from the fingertip is exposed to the outside air, and although the two tests using FRAS4 are cheap and reportedly accurate [23], we were concerned that the effect of the oxidation of blood samples may lead to some bias. Therefore, we used a fresh serum sample, without exposure to the outside air, for the ROM and BAP tests. We obtained fresh serum samples by centrifuging the blood at 3,000 r.p.m. for 10 minutes, immediately (within 10 minutes) after the blood was collected. The obtained serum samples were stored at $-20^{\circ} \mathrm{C}$ until assayed. In addition, these serum samples were analyzed within 3 days after drawing the blood, to ensure the freshness of the serum.

According to the manufacturer's recommendations, a $10 \mu \mathrm{L}$ serum sample and $1 \mathrm{~mL}$ of solution buffer (R2 reagent of kit, $\mathrm{pH} 4.8$ ) were mixed in a cuvette, and $10 \mu \mathrm{L}$ of the chromogenic substrate (R1 reagent) was added to the cuvette. After mixing and centrifugation for 60 seconds, the cuvette was incubated in a thermostatic block for 5 minutes at $37^{\circ} \mathrm{C}$. The absorbance at $505 \mathrm{~nm}$ was then recorded. The measurement values are represented by Carratelli units (U.CARR), where 1 U.CARR corresponds to $0.8 \mathrm{mg} / \mathrm{L} \mathrm{H}_{2} \mathrm{O}_{2}$. To determine the BAP levels, $50 \mu \mathrm{L}$ of the $\mathrm{R} 2$ reagent (ferric chloride) was added to the cuvette containing the $\mathrm{R} 1$ reagent (thiocyanate derivative), and the absorbance was measured to obtain the reagent blank value. A $10 \mu \mathrm{L}$ portion of the serum sample was then added to the cuvette. After an incubation for 5 minutes at $37^{\circ} \mathrm{C}$, the absorbance at 505 $\mathrm{nm}$ was recorded. The BAP levels were expressed as $\mu \mathrm{mol} / \mathrm{L}$. The manufacturer's (Diacron) standards stated that the desirable range of ROM levels is $250-300$ U.CARR $[15,22]$, and that sufficient BAP levels are higher than $2,200 \mu \mathrm{mol} / \mathrm{L}[20,21]$.

\section{Statistics}

Fundamentally, the statistical analyses in present study were conducted for each sex and each group, and were compared between male and female or among subgroups, respectively. The mean values and standard deviations of ROM and BAP were calculated. Moreover, we determined the Oxidative stress-Antioxidant capacity ratio (OAR), using the ROM and BAP values, in order to clarify each characteristic of the subgroups. Regarding this OAR analysis, Sharma et al. [24] reported that the composite reactive oxygen species (ROS)-total antioxidant capacity (TAC) score is a novel measure of oxidative stress and is superior to ROS or TAC alone, in discriminating between fertile and infertile men. In ruminant medicine, the information on oxidative stress is more accurate when using combined ROM and BAP data than when using them separately $[25,26]$. The OAR was calculated as follows: BAP / ROM / divided by the geometrical mean of BAP / ROM. Since the total mean of the OAR value corresponds to 1.0 , the OAR value for each group may be interpreted as follows: values higher than 1.0 indicate high antioxidant ability, whereas those less than 1.0 show low antioxidant ability.

The height, body weight, BMI, and sleep duration were also analyzed as continuous variables. Therefore, the gender or subgroup differences for these variables were detected by a t-test or a one-way analysis of variance (ANOVA). In addition to the ANOVA analysis, multiple comparisons among the subgroups were conducted with Scheffe's test. The following 16 items were analyzed as categorical variables: 'aerobic exercise, 'anaerobic exercise', 'strength training, 'soybean intake', 'potato intake,' 'seaweed intake, 'bean curd intake, 'fruit intake, 'pork intake, 'chicken intake, 'beef intake, 'light-colored vegetable intake', 'green or yellow colored vegetable intake', 'salty confectionery intake', 'chocolate-like sweets intake', and 'soft drink intake'. Since comparative analyses for these 16 items require nonparametric tests, the subgroup differences were extracted by a Kruskal-Wallis test. The relationships between ROM, BAP, and OAR with related factors were analyzed with partial correlation coefficients, except for the effects of gender difference. Moreover, a multiple regression analysis with a stepwise procedure was conducted to reveal the significant factors for ROM, BAP, and OAR, as dependent variables. Since the distributions of these three markers were skewed, the log-transformed values of ROM, BAP, and OAR, which showed normal distributions, were used in the stepwise multiple regression analysis. All data were analyzed using the SPSS software, version 14.0 (SPSS Japan Inc., Tokyo, Japan). 
Kazuyoshi Tamae (2019) The Associations of Reactive Oxygen Metabolites and Biological Antioxidant Potentials with Related Factors in Healthy Youth

\section{Results}

The profiles, physical characteristics, and sleeping durations in each group are outlined in Table 1 . As the statistical results, the ANOVA test indicated that the height, weight, and BMI values of the male subjects were higher in UA than in HS and HA $(\mathrm{P}<0.05 \sim 0.01)$. According to the t-test, the BMI values in $\mathrm{HA}$ and $\mathrm{UA}$ were higher in males than in females $(\mathrm{P}<0.01$ and $\mathrm{P}<0.05)$. In addition, the sleeping durations in HA were greater in males than in females $(\mathrm{P}<0.001)$.

The ROM (U.CARR) level for the total subjects was $249.28 \pm$ 51.46. A 4.61-fold interindividual variation was found $(\min =99$, $\max$ = 456). Similarly, the BAP level $(\mu \mathrm{mol} / \mathrm{L})$ was $2,478.36 \pm 276.59$, with a 1.92 -fold interindividual variation $(\min =1,684, \max =3,231)$. The OAR level was $1.00 \pm 0.23(\min =0.48, \max =2.61$, interindividual variation $=5.44$-fold). The mean values $(\mathrm{SD})$ of $\mathrm{ROM}, \mathrm{BAP}$, and OAR by gender or groups are shown in Table 1. The ANOVA test revealed that the ROM levels in male subjects were significantly different across the three groups $(\mathrm{P}<0.01)$. Similarly, the BAP levels in both male and female subjects were significantly different among the three groups $(\mathrm{P}<0.001$ and $\mathrm{P}<0.05)$. For the OAR results, the male value was significant higher than the female value $(\mathrm{P}<0.001)$. Additionally, a significant positive association was observed between the ROM level and the BAP level in the entire sample $(\mathrm{P}<0.05)$.

Table 1. Subjects' characteristics, reactive oxygen metabolites (ROS), biological antioxidant potentials (BAP), and oxidative stress-antioxidant capacity ratio (OAR) among HS group, HA group, and UA group.

\begin{tabular}{|c|c|c|c|c|c|}
\hline \multicolumn{2}{|l|}{ Items } & \multirow{2}{*}{$\begin{array}{c}\begin{array}{c}\text { HS } \\
(\mathbf{n}=113)\end{array} \\
50(44.2) \\
63(55.8)\end{array}$} & \multirow{2}{*}{$\begin{array}{c}\begin{array}{c}\text { HA } \\
(\mathbf{n}=\mathbf{2 1 6})\end{array} \\
143(66.2) \\
73(33.8)\end{array}$} & \multirow{2}{*}{$\begin{array}{c}\begin{array}{c}\text { UA } \\
(\mathbf{n}=\mathbf{4 1})\end{array} \\
33(80.5) \\
8(19.5)\end{array}$} & \multirow{2}{*}{$\begin{array}{r}\text { F } \\
-\end{array}$} \\
\hline Gender $(\mathrm{n} \bullet / 0)$ & $\begin{array}{l}\text { male }(\mathrm{m}) \\
\text { female }(\mathrm{f})\end{array}$ & & & & \\
\hline Age ( mean-SD ) & & $16.70 \pm 0.92$ & $16.22 \pm 0.72$ & $20.20 \pm 1.36$ & - \\
\hline Height (cm·SD) & $\begin{array}{l}\mathrm{m} \\
\mathrm{f}\end{array}$ & $\begin{array}{l}163.55 \pm 24.81 \\
153.09 \pm 20.13\end{array}$ & $\begin{array}{c}166.53 \pm 18.5 \\
155.92 \pm 14.26\end{array}$ & $\begin{array}{l}175.62 \pm 0.60 \\
163.56 \pm 5.49\end{array}$ & $\begin{array}{l}4.27 * \\
1.40\end{array}$ \\
\hline Weight (kg-SD) & $\begin{array}{l}\mathrm{m} \\
\mathrm{f}\end{array}$ & $\begin{array}{l}58.35 \pm 8.71 \\
49.93 \pm 4.99\end{array}$ & $\begin{array}{l}61.02 \pm 11.29 \\
50.19 \pm 6.36\end{array}$ & $\begin{array}{l}66.44 \pm 4.94 \\
54.51 \pm 1.38\end{array}$ & $\begin{array}{l}6.41 * * \\
2.09\end{array}$ \\
\hline BMI (mean-SD) & $\begin{array}{l}\mathrm{m} \\
\mathrm{f} \\
\mathrm{t}\end{array}$ & $\begin{array}{c}19.74 \pm 4.89 \\
20.23 \pm 2.01 \\
-0.07\end{array}$ & $\begin{array}{c}21.23 \pm 3.84 \\
20.15 \pm 1.81 \\
2.62 * *\end{array}$ & $\begin{array}{c}21.54 \pm 1.28 \\
20.43 \pm 1.37 \\
2.05^{*}\end{array}$ & $\begin{array}{l}3.09 * \\
0.08\end{array}$ \\
\hline Sleeping time $(\min -\mathrm{SD})$ & $\begin{array}{l}\mathrm{m} \\
\mathrm{f} \\
\mathrm{t}\end{array}$ & $\begin{array}{c}365.76 \pm 55.81 \\
347.45 \pm 84.17 \\
1.26\end{array}$ & $\begin{array}{c}375.30 \pm 59.12 \\
344.12 \pm 55.61 \\
3.62 * * *\end{array}$ & $\begin{array}{c}393.79 \pm 64.71 \\
395.63 \pm 49.82 \\
-0.08\end{array}$ & $\begin{array}{l}2.18 \\
2.02\end{array}$ \\
\hline ROM (U.CARR) & $\begin{array}{c}\mathrm{m} \\
\mathrm{f} \\
\mathrm{t} \\
\text { total }\end{array}$ & $\begin{aligned} & 244.32 \pm 46.22 \\
& 266.97 \pm 57.08 \\
&-2.28^{*} \\
& 256.95 \pm 53.54\end{aligned}$ & $\begin{aligned} & 244.71 \pm 48.14 \\
& 265.26 \pm 52.47 \\
&-2.88 * * \\
& 251.66 \pm 50.47\end{aligned}$ & $\begin{aligned} 211.12 & \pm 36.49 \\
234.38 & \pm 34.53 \\
-1.63 & \\
215.66 & \pm 36.89\end{aligned}$ & $\begin{array}{c}7.4 * * \\
1.33 \\
10.776 * * *\end{array}$ \\
\hline $\mathrm{BAP}(\mu \mathrm{mol} / \mathrm{L})$ & $\begin{array}{c}\mathrm{m} \\
\mathrm{f} \\
\mathrm{t} \\
\text { total }\end{array}$ & $\begin{aligned} 2424.18 & \pm 259.04 \\
2426.76 & \pm 217.98 \\
- & 0.06 \\
2425.62 & \pm 235.93\end{aligned}$ & $\begin{array}{rl}2582.18 & \pm 299.71 \\
2464.41 & \pm 238.13 \\
3.14 & * * \\
2542.37 & \pm 285.37\end{array}$ & $\begin{aligned} 2306.42 & \pm 214.48 \\
2203.88 & \pm 183.58 \\
1.24 & \\
2286.41 & \pm 210.70\end{aligned}$ & $\begin{array}{r}15.78 * * * \\
4.80 * \\
19.489 * * *\end{array}$ \\
\hline $\begin{array}{l}\text { OAR (Oxidative stress - } \\
\text { Antioxidant capacity ratio) }\end{array}$ & $\begin{array}{c}\mathrm{m} \\
\mathrm{f} \\
\mathrm{t} \\
\text { total }\end{array}$ & $\begin{array}{c}0.98 \pm 0.16 \\
0.92 \pm 0.21 \\
1.85 \\
0.95 \pm 2.00\end{array}$ & $\begin{array}{c}1.06 \pm 0.26 \\
0.93 \pm 0.19 \\
3.79 * * * \\
1.02 \pm 0.25\end{array}$ & $\begin{array}{c}1.09 \pm 0.21 \\
0.93 \pm 0.19 \\
1.91 \\
1.06 \pm 0.21\end{array}$ & $\begin{array}{l}2.466 \\
0.078\end{array}$ \\
\hline
\end{tabular}

Note 1: High school student group, high school athletes, and university athletes are shown as HS, HA, and UA, respectively.

Note 2: t-test was applied to detect gender difference in each group, showing $t$ values and asterisk.

Note 3: ANOVA was applied to detect the subgroup difference in each gender, showing F values and asterisk.

Statistical significance levels are as follows : $* \mathrm{P}<0.05 * * \mathrm{P}<0.01 * * * \mathrm{P}<0.001$ 
(Table 2) shows the response patterns of the 16 categories of lifestyle items in each group. The Kruskal-Wallis test revealed that the frequencies of 'anaerobic exercise, 'aerobic exercise, 'strength training', 'soybean', 'potato', and 'seaweed' were remarkable higher in the UA group than in the other groups ( $\mathrm{P}<0.001$ for all). Conversely, 'pork' and'light-colored vegetable' were lower in the UA group as compared with the other two groups $(\mathrm{P}<0.05$ and $\mathrm{P}<0.01)$.

(Table 3) shows the associations between the three markers and related factors. For the continuous and nominal variables, the items significantly related to the ROM level were 'age' $(\mathrm{r}=-0.21, \mathrm{P}<0.001)$, 'height' $(\mathrm{r}=-0.23, \mathrm{P}<0.001)$, 'gender' $(\mathrm{r}=0.18, \mathrm{P}<0.001)$, 'school' $(\mathrm{r}=-0.19, \mathrm{P}<0.001)$, and 'subgroup' $(\mathrm{r}=-0.14, \mathrm{P}<0.01)$. The items related to the BAP level were 'age' $(\mathrm{r}=-0.26, \mathrm{P}<0.001)$, 'gender' $(\mathrm{r}=$ $-0.11, \mathrm{P}<0.05)$, 'school' $(\mathrm{r}=-0.21, \mathrm{P}<0.001)$ and 'extracurricular sports activity' $(\mathrm{r}=-0.10, \mathrm{P}<0.05)$. The OAR level was significantly correlated to 'height' $(\mathrm{r}=0.17, \mathrm{P}<0.01)$, 'weight' $(\mathrm{r}=0.11, \mathrm{P}<0.05)$, 'gender' $(\mathrm{r}=-0.23, \mathrm{P}<0.001)$, 'subgroup' $(\mathrm{r}=0.13, \mathrm{P}<0.001)$, and 'extracurricular sports activity' $(\mathrm{r}=0.12, \mathrm{P}<0.01)$.

Table 2. Distributions (\%) of lifestyle factors in high school students (HSS), high school athletes (HSA), and university athletes (UA)

\begin{tabular}{|c|c|c|c|c|c|c|c|c|c|c|c|}
\hline \multicolumn{2}{|c|}{ Factors \& Items } & \multicolumn{3}{|c|}{$\begin{array}{c}\text { HS } \\
(m=50, f=63)\end{array}$} & \multicolumn{3}{|c|}{$\begin{array}{c}\text { HA } \\
(m=143, f=73)\end{array}$} & \multicolumn{3}{|c|}{$\begin{array}{c}\text { UA } \\
(m=33, f=8)\end{array}$} & \multirow[t]{2}{*}{$\chi^{2}$} \\
\hline & & $\begin{array}{l}\text { Not or } \\
\text { rarely }\end{array}$ & Moderate & $\begin{array}{l}\text { Almost } \\
\text { regular }\end{array}$ & $\begin{array}{l}\text { Not or } \\
\text { rarely }\end{array}$ & Moderate & $\begin{array}{l}\text { Almost } \\
\text { regular }\end{array}$ & $\begin{array}{l}\text { Not or } \\
\text { rarely }\end{array}$ & Moderate & $\begin{array}{l}\text { Almost } \\
\text { regular }\end{array}$ & \\
\hline \multirow{3}{*}{ Daily exercise } & $\begin{array}{l}\text { Anaerobic } \\
\text { training }\end{array}$ & 54.7 & 44.7 & 0.6 & 18.6 & 74.4 & 7.0 & 7.6 & 68.8 & 23.6 & $23.47 * * *$ \\
\hline & Aerobic training & 53.6 & 43.7 & 2.6 & 27.8 & 63.9 & 8.3 & 8.2 & 70.7 & 21.1 & $11.11 * * *$ \\
\hline & Strength training & 58.6 & 41.4 & 0.0 & 22.2 & 77.8 & 0.0 & 7.8 & 65.4 & 26.8 & $36.59 * * *$ \\
\hline \multirow{5}{*}{$\begin{array}{l}\text { Healthy food } \\
\text { intake }\end{array}$} & Soybean & 33.3 & 66.3 & 0.4 & 37.5 & 57.8 & 4.7 & 11.7 & 26.7 & 61.7 & 109.45 *** \\
\hline & Potato & 30.6 & 68.8 & 0.7 & 35.1 & 57.6 & 7.3 & 21.3 & 40.0 & 38.7 & $54.76 * * *$ \\
\hline & Seaweed & 33.1 & 60.6 & 6.3 & 28.2 & 65.0 & 6.8 & 28.2 & 43.6 & 28.2 & $17.33 * * *$ \\
\hline & Bean curd & 33.3 & 57.2 & 9.4 & 30.4 & 60.0 & 9.6 & 26.8 & 57.7 & 15.5 & 1.25 \\
\hline & Fruits & 33.6 & 55.9 & 10.5 & 26.5 & 63.7 & 9.7 & 30.7 & 56.1 & 13.2 & 0.26 \\
\hline \multirow{3}{*}{ Meat intake } & Pork & 30.2 & 54.0 & 15.9 & 29.4 & 58.3 & 12.3 & 32.5 & 60.8 & 6.7 & $3.92 *$ \\
\hline & Chicken & 28.1 & 53.1 & 18.8 & 32.1 & 58.4 & 9.5 & 29.3 & 61.2 & 9.5 & 2.48 \\
\hline & Beef & 34.2 & 59.2 & 6.6 & 30.6 & 57.2 & 12.1 & 28.1 & 59.5 & 12.4 & 0.84 \\
\hline \multirow[b]{2}{*}{ Vegetable intake } & Light-colored & 26.4 & 47.2 & 26.4 & 27.1 & 57.9 & 15.0 & 34.2 & 62.0 & 3.8 & 21.91 ** \\
\hline & $\begin{array}{l}\text { Green or yellow- } \\
\text { colored }\end{array}$ & 29.0 & 56.5 & 14.5 & 27.0 & 58.4 & 14.6 & 33.9 & 59.1 & 7.0 & 3.80 \\
\hline \multirow{3}{*}{$\begin{array}{l}\text { Eating between } \\
\text { meals }\end{array}$} & $\begin{array}{l}\text { Salty } \\
\text { confectionery }\end{array}$ & 28.8 & 58.5 & 12.7 & 32.5 & 58.1 & 9.4 & 34.1 & 58.5 & 7.3 & 1.12 \\
\hline & $\begin{array}{l}\text { Chocolate-like } \\
\text { sweets }\end{array}$ & 25.3 & 2.3 & 12.3 & 29.4 & 60.3 & 10.3 & 40.9 & 48.9 & 10.2 & $<0.01$ \\
\hline & Soft drinks & 34.3 & 57.6 & 8.1 & 29.6 & 54.8 & 15.7 & 24.1 & 65.1 & 10.8 & 0.60 \\
\hline
\end{tabular}

Note: Kruskal-Warris test was conducted in order to detect statistical differences among sub-groups, shown as $X$ score and asterisks. .Statistical significance levels are as follows: $* \mathrm{P}<0.05$ $* * \mathrm{P}<0.01 * * * \mathrm{P}<0.001$

Additionally, to detect the authentic correlation between these markers and the lifestyle factors, we collectively conducted a partial correlations analysis for the entire sample, with the elimination of the influences of gender and school differences Table 3. The ROM level was significantly inversely correlated to 'soybean' $(\mathrm{r}=-0.13, \mathrm{P}<0.05)$, 'pork' $(\mathrm{r}=-0.11, \mathrm{P}<0.05)$, 'chicken' $(\mathrm{r}=-0.12, \mathrm{P}<0.05)$, and 'beef' $(\mathrm{r}$ $=-0.13, \mathrm{P}<0.05)$, whereas the BAP level was not significantly related to all lifestyle items. The OAR level was significant associated with 'soybean' $(\mathrm{r}=0.14, \mathrm{P}<0.05)$, 'pork' $(\mathrm{r}=0.10, \mathrm{P}<0.05)$, 'chicken' $(\mathrm{r}=$ $0.13, \mathrm{P}<0.05)$, and 'beef' $(\mathrm{r}=-0.12, \mathrm{P}<0.05)$.
The results of the multiple regression analyses of BAP, ROM, and OAR by the stepwise method are shown in (Table 4). Due to the significant correlations between 'BMI' and 'weight' $(\mathrm{r}=0.85, \mathrm{P}$ $<0.001)$, or 'extracurricular sports activity' and 'subgroup' $(r=0.86$, $\mathrm{P}<0.001$ ), the weight'and 'subgroup' items were not included in the analysis, in order to avoid collinearity. Accordingly, the following 23 items were used the in analysis as the independent variables: 'age', 'height,' 'BMI', 'sleep duration', 'gender (male $=0$, female $=1$ )', 'school (high school $=0$, university $=1$ ), ' 'extracurricular sports activity (not attend $=0$, attend $=1$ ), as well as the 16 lifestyle items. As the results, 
Kazuyoshi Tamae (2019) The Associations of Reactive Oxygen Metabolites and Biological Antioxidant Potentials with Related Factors in Healthy Youth

the ROM level of 'gender' $(\mathrm{P}<0.001)$ was significantly increased, whereas 'soybean' $(\mathrm{P}<0.001)$ decreased it. These two independent factors obtained from the multiple regression analysis explain $11 \%$ of the entire variation. Similarly, 'gender' $(\mathrm{P}<0.01)$ and 'soybean'
$(\mathrm{P}<0.001)$ had significantly decreased BAP levels, with only $3 \%$ variance explained. Finally, the OAR value of 'soybean' $(\mathrm{P}<0.01)$ was significantly increased, while that of 'gender' $(\mathrm{P}<0.01)$ was significant decreased, explaining $10 \%$ of the total variance.

Table 3 Associations of BAP, ROM, and OAR with related factors.

\begin{tabular}{|c|c|c|c|}
\hline Factors and Items & ROM & BAP & OAR \\
\hline \multicolumn{4}{|l|}{$\begin{array}{l}\text { Demographic, physique, sleeping time factors } \\
\text { continuous variables a) }\end{array}$} \\
\hline Age & $-0.21 * * *$ & $-0.26 * * *$ & 0.06 \\
\hline Height & $-0.23 * * *$ & -0.04 & $0.17 * *$ \\
\hline Weight & -0.07 & 0.07 & $0.11 *$ \\
\hline BMI & 0.09 & -0.05 & -0.09 \\
\hline Sleeping time (in weekday) & -0.05 & 0.07 & 0.08 \\
\hline \multicolumn{4}{|l|}{ Nominal variables ${ }^{b)}$} \\
\hline Gender $($ male $=0$, female $=1)$ & $0.18 * * *$ & $-0.11 *$ & $-0.23 * * *$ \\
\hline School (High school=0, University $=1$ ) & $-0.19 * * *$ & $-0.21 * * *$ & 0.07 \\
\hline Subgroup $(\mathrm{HS}=0, \mathrm{HA}=1, \mathrm{UA}=2)$ & $-0.14 * *$ & -0.01 & $0.13 * *$ \\
\hline Extracurricular sports activity (no $=0$, yes $=1$ ) & -0.07 & $0.10 *$ & $0.12 * *$ \\
\hline \multicolumn{4}{|l|}{ Life style factors $\left.{ }^{c}\right)$} \\
\hline \multicolumn{4}{|l|}{ Daily exercise } \\
\hline Anaerobic training & -0.07 & 0.05 & 0.08 \\
\hline Aerobic training & -0.10 & -0.04 & 0.04 \\
\hline Strength training & -0.10 & -0.08 & 0.04 \\
\hline \multicolumn{4}{|l|}{ Healthy foods intake } \\
\hline Soybean & $-0.13 *$ & 0.03 & $0.14 * *$ \\
\hline Potato & -0.05 & 0.01 & 0.02 \\
\hline Seaweed & -0.05 & -0.01 & 0.04 \\
\hline Bean curd & -0.03 & -0.03 & 0.02 \\
\hline Fruits & -0.01 & 0.00 & 0.00 \\
\hline \multicolumn{4}{|l|}{ Meat intake } \\
\hline Pork & $-0.11 *$ & -0.01 & $0.10 *$ \\
\hline Chicken & $-0.12 *$ & -0.02 & $0.13 *$ \\
\hline Beef & $-0.13 *$ & -0.01 & $0.12 *$ \\
\hline \multicolumn{4}{|l|}{ Vegetable intake } \\
\hline Light-colored & 0.01 & 0.05 & 0.00 \\
\hline Green or yellow-colored & 0.00 & -0.02 & -0.02 \\
\hline \multicolumn{4}{|l|}{ Eating between meals } \\
\hline Salty confectionery & 0.01 & 0.01 & 0.02 \\
\hline Chocolate-like sweets & 0.01 & -0.01 & -0.03 \\
\hline Soft drinks & -0.01 & 0.07 & 0.18 \\
\hline
\end{tabular}

a) Pearson's correlation coefficient was applied.

b) Spearman's correlation coefficient was applied.

c) Partial correlation coefficient without the influences of gender and school, were applied.

Statistical significance levels are as follows: $* \mathrm{P}<0.05 * * \mathrm{P}<0.01 * * * \mathrm{P}<0.001$ 
Table 4. Stepwise multiple regression of $\log \mathrm{BAP}, \log \mathrm{ROM}$, and $\log \mathrm{OAR}$, against related factors

\begin{tabular}{|c|c|c|c|c|c|c|}
\hline Dependent a) & Independent b) & Partial $\mathbf{r}^{\mathrm{c}}$ ) & SE & $\begin{array}{l}\text { Standardized } \\
\text { coefficients }\end{array}$ & $\mathbf{R}^{2}$ & Adjusted $R^{2}$ \\
\hline \multicolumn{7}{|l|}{ Log ROM } \\
\hline & Gender & 0.09 & 0.02 & $0.24 * * *$ & \multirow{2}{*}{0.111} & \multirow{2}{*}{0.106} \\
\hline & Soybean & -0.06 & 0.01 & $-0.21 * * *$ & & \\
\hline \multicolumn{7}{|l|}{ Log BAP } \\
\hline & Gender & -0.03 & 0.01 & $-0.15 * *$ & \multirow{2}{*}{0.031} & \multirow{2}{*}{0.026} \\
\hline & Soybean & -0.02 & 0.01 & $-0.10 *$ & & \\
\hline \multicolumn{7}{|l|}{ Log OAR } \\
\hline & Gender & -0.12 & 0.02 & $-0.30 * * *$ & \multirow{2}{*}{0.120} & \multirow{2}{*}{0.115} \\
\hline & Soybean & 0.04 & 0.01 & $0.15 * *$ & & \\
\hline
\end{tabular}

a) Log transformed BAP, ROM, OAR

b) Gender $($ male $=0$, female $=1)$

c) Partial $r$ indicates partial regression coefficient.

Statistical significance levels are as follows : * $\mathrm{P}<0.05 * * \mathrm{P}<0.01 * * * \mathrm{P}<0.001$

\section{Discussion}

\section{Levels of ROM, BAP, and OAR}

We obtained fine ROM and BAP results that reflected the good status without gender or subgroup distinction among the present subjects. The ROM level in present subjects was remarkably lower than those in senior subjects [27-31], hemodialyzed patients [1], chronic obstructive pulmonary disease (COPD) patients [32, 33], asthma patients [34], periodontitis patients [35, 36], atherosclerosis patients [37], and obstructive sleep apnea patients [38]. Meanwhile, the present BAP level for all present subjects was slightly higher than those of healthy adults [32,39]. As stated by Olinski [40], oxidative stress and oxidative DNA damage are probably contributing factors in aging. Specifically, the ROM level was positively associated with age $[19,39]$, whereas the BAP level was inversely correlated with age [19]. These previous findings support our present results, which indicated lower levels of both ROM and BAP.

A significant positive correlation between ROM and BAP was observed. This result is consistant with that in healthy middle-aged subjects [31]. As described by Halliwell [41], the production of reactive species in healthy aerobes is generally balanced with the antioxidant defense systems. The antioxidant level may change in proportion to the oxidative stress status. Therefore, our findings may be supported by Halliwell's conclusions [41]. Based on the proportional association of ROM with BAP, the obtained OAR level may indicate that the antioxidant capacity was higher in males than in females, or in exercised subjects than in non-exercised subjects. For healthy adolescents or youth, the OAR level may be considered as a useful marker for investigating the actual association between oxidative stress, antioxidant capacity, and related factors, such as lifestyle.

\section{Factors related to ROM, BAP, and OAR levels}

The distributions of the various exercise statuses and the dietary intake were analyzed for the present subjects (Table 2). The frequencies of 3 items, composed of daily exercise, the consumption of 3 or more healthy foods, and the vegetable intake were remarkably higher in the UA group than in the HA or OA groups, irrespective of gender. These results are considered to be meaningful information, reflecting the characteristics of each subgroup. The Pearson's and Spearman's correlation analyses indicated that the ROM, BAP, and OAR levels were significantly associated with several demographic and physical factors. The characteristics of these results were explained as follows: daily exercising subjects or male subjects have lower values of ROM and BAP, and higher values of OAR.

With regard to the influences of exercise on ROM, the level reportedly demonstrated a reverse correlation with the handgrip strength [28]. Additionally, the ROM values in the present university subjects containing Olympic candidates were lower, and equivalent to those of elite woman volleyball athletes in Serbia [42]. Various studies have observed an adaptation in the body's antioxidant defense system as a result of aerobic exercise $[43,44]$ and anaerobic exercise $[45,46]$. Therefore, the ROM, BAP, and OAR levels among healthy youth, such as the present subjects, may be associated with substantial aerobic/ anaerobic abilities, rather than exercise frequencies as mere practice. On the other hand, a significant association between the ROM level and high-sensitivity C-reactive protein, as an inflammatory marker, was reported [47]. Therefore, the ROM level may increase due to muscle injury from exercise. Acute exercise can stimulate an increase in reactive oxygen/nitrogen species (RONS) and subsequent oxidative stress [48]. The ROM level in elite athletes fluctuated between before and after the training period [42]. Moreover, other oxidative stress markers, such as malondialdehyde (MDA) and lipidhydroperoxides (LOOP), were reported as independent variables to the ROM level as a dependent variable [42]. Considering these previous findings, the validity or reliability of our findings should be confirmed according to an appropriately designed study that can reveal the type, duration, and intensity of exercise, as well as the associations with other oxidative stress markers. 
The partial correlation analysis revealed that the ROM level was inversely and significantly correlated with the consumption of 'soybean', 'pork', 'chicken', and 'beef'. Conversely, the OAR level was significantly and positively associated with those 4 variables. Among them, the 'pork', 'chicken', and 'beef'consumption levels were significantly related to ROM and OAR, which was unexpected. For instance, the ROM level in people who generally have a high calorie dietary intake (meat, butter, oil, etc.) and scarcely consume vegetable or fruits, was striking higher than that in another people with a healthier dietary intake [28, 49]. However, the oxidative stress level was reportedly correlated with imidazole dipeptides, anserine and carnosine, found in various meats, as an antioxidant [50]. These are widely distributed in vertebrate organisms and are particularly abundant in skeletal muscle [50], and especially in chicken breast. However, their concentrations reportedly vary widely with species and muscle types, and are found in greater concentrations in muscle high in white fibers, with chicken white muscle fibers containing over five-fold more anserine and carnosine than the red fibers [51].

Therefore, the validity and reliability of the present results must be confirmed, using an improved questionnaire to investigate the types, parts, and preparation methods of the consumed meats.

As for 'soybean', the stepwise multiple regression analysis also revealed that increases of ROM and OAR, and a decrease of BAP were predicted, due to the increased amount of 'soybean'consumed. As reported by Wijeratne et al. [52], the effects of the soy isoflavones genistein and daidzein on antioxidant enzymes were dependent upon the compound and its concentration. In addition, DNA damage is significantly inversely correlated to the plasma isoflavone concentrations, among healthy young subjects [53]. Similarly, for young subjects, the positive effects of soy protein consumption on the plasma total antioxidant status were observed [54]. Based on these previous findings, we should confirm the validity and reliability of the present BAP results, using other blood antioxidant markers, simultaneously. Similarly, the difference of 'gender' was significantly related to the ROM, BAP, and OAR levels, not only in part of the univariate analyses, but also in the multivariate analysis. These results were in inverse proportion to previous findings [48, 55-57], which indicated significant lower levels of MDA in women than in men. These results may be due in part to the higher estrogen concentration [48], which is known to possess antioxidant properties. As one of the reasons, we could consider the fact that the present subjects were very healthy adolescents or youths. In the future, to reveal the gender differences between ROM, BAP, and OAR, we will conduct the same type of investigation with samples from adolescent-aged subjects and middle-aged and elderly subjects.

In premenopausal females, the measurements of oxidative stress were considered to potentially fluctuate during the menstrual cycle. As stated by Wactawski-Wende et al. [58], the human menstrual cycle includes cycle-related changes in estrogen and other endogenous hormone concentrations that may impact oxidative stress levels. Therefore, we should consider the influences of the menstrual cycle on the oxidative ROM, BAP, and OAR levels.

\section{Future issues}

Lastly, we must describe that the current study suffers from several possible problems and limitations. First, the interpretation of the present results is limited because of the questionnaire design. For instance, Table 2 indicated high "moderate" quantities for almost all of the foods/meals. The answer frame consisted of a three-point scale for our lifestyle factors items, allowing some ambiguity in the interpretation of these results. In the future, in order to explain the present findings, a questionnaire using a five- or more anchor point scale may be required. Second, the height and weight data were not based on measurements on the blood sampling day. Particularly, the weight data were obtained according to self-measurement at home on the morning of the blood collection. Therefore, their values may have some uncertainly, and may not necessarily provide completely accurate data for the BMI. Third, factors that may influence the serum marker data, such as the time of venous blood collection or the elapsed time after a meal or exercise, were not investigated in detail. From the limitations and problems described above, the present findings should be extended through a more precisely designed epidemiological study. In particular, a comparison between the present results and those obtained with another population sample, such as elderly subjects, should be considered.

\section{Acknowledgment}

This work was supported in part by a Grant-in-Aid for Scientific Research from the Ministry of Education, Culture, Sports, Science, and Technology of Japan (15K12702). We wish to thank the principals, the vice-principals, of Fukuoka Prefectural Nakama High School, Fukuoka Prefectural Hokuchiku High School, and Fukuoka Prefectural Wakamatsu High School for their support of this work. Especially among them, we are very grateful to two teachers, Mr. Hisao Wakizoe, and Mr. Kunihiro Shiraki.

\section{References}

1. Nakayama K, Terawaki H, Nakayama M, Iwabuchi M, Sato T, Ito S (2007) Reduction of serum antioxidative capacity during hemodialysis. Clin Exp Nephrol 11: $218-224$

2. Irie M, Tamae K, Iwamoto-Tanaka N, Kasai H (2005) Occupational and lifestyle factors and urinary 8-hydroxydeoxyguanosine. Cancer Sci 96: 600-606.

3. Tamae K, Kawai K, Yamasaki S, Kawanami K, Ikeda M, et al (2009) Effect of age, smoking and other lifestyle factors on urinary 7-methylguanine and 8-hydroxydeoxyguanosine. Cancer Sci 100: 715-721.

4. Hata I, Kaji M, Hirano S, Shigematsu Y, Tsukahara H, Mayumi M (2006) Urinary oxidative stress markers in young patients with type 1 diabetes. Pediatr Int 48: $58-61$.

5. Woo J, Yeo NH, Shin KO, Lee HJ, Yoo J, Kang S (2010) Antioxidant enzyme activities and DNA damage in children with type 1 diabetes mellitus after 12 weeks of exercise. Acta Paediatr 99: 1263-1268.

6. Tsukahara H, Sekine K, Uchiyama M, Kawakami H, Hata I, et al (2003) Formation of advanced glycosylation end products and oxidative stress in young patients with type 1 diabetes. Pediatr Res 54: 419-424.

7. Martino F, Pignatelli P, Martino E, Morrone F, Carnevale R, et al (2007) Early increase of oxidative stress and soluble CD40L in children with hypercholesterolemia. $J \mathrm{Am}$ Coll Cardiol 49: 1974-1981.

8. Omata N, Tsukahara H, Ito S, Ohshima Y, Yasutomi M, et al (2001) Increased oxidative stress in childhood atopic dermatitis. Life Sci 69: 223-228.

9. Shimizu T, Lee T, Shoji H, Kudo T, Satoh Y, Yamashiro Y (2003) Urinary 8-hydroxydeoxyguanosine excretion in children before and after therapy for eradication of Helicobacter pylori infection. Acta Paediatr 92: 1026-1028.

10. Drury JA1, Jeffers G, Cooke RW (1998) Urinary 8-hydroxydeoxyguanosine in infants and children. Free Radic Res 28: 423-428. [crossref] 
11. Fukuda M, Yamauchi H, Yamamoto H, Aminaka M, Murakami H, et al (2008) The evaluation of oxidative DNA damage in children with brain damage using 8-hydroxydeoxyguanosine levels. Brain and Development 30: 131-136.

12. Stewart RJ, Askew EW, McDonald CM, Metos J, Jackson WD, et al (2002) Antioxidant status of young children: response to an antioxidant supplement. $J \mathrm{Am}$ Diet Assoc 102: 1652-1657.

13. Tamura S, Tsukahara H, Ueno M, Maeda M, Kawakami H, et al (2006) Evaluation of a urinary multi-parameter biomarker set for oxidative stress in children, adolescents and young adults. Free Radic Res 40: 1198-1205.

14. Kelishadi R, Sharifi M, Khosravi A, Adeli K (2007) Relationship Between C-Reactive Protein and Atherosclerotic Risk Factors and Oxidative Stress Markers Among Young Persons 10-18 Years Old. Clin Chem 53: 456-464.

15. Trotti R, Carratelli M, Barbieri M et al (2001) Oxidative stress and a thrombophilic condition in alcoholics without severe liver disease. Haematologica 86: 85-91.

16. Dani C, Martelli E, Bertini G, Pezzati M, Filippi L, et al (2003) Plasma bilirubin level and oxidative stress in preterm infants. Arch Dis Child Fetal Neonatal Ed 88: 119-123.

17. Yagi K, Ohkawa H, Onishi N, Yamashita M, Nakashima T (1981) Lesion of aortic intima caused by intravenous administration of linoleic acid hydroperoxide. $J \mathrm{Appl}$ Biochem 3: 58-65.

18. Carratelli M, Porcaro L, Ruscica M, De Simone E, Bertelli AAE, et al (2001) Reactive oxygen metabolites and prooxidant status in children with Down's syndrome. Int J Clin Pharmacol Res 21: 79-84.

19. Komatsu F, Kudoh H, Kagawa Y (2007) Evaluation of oxidative stress and effectiveness of low-dose glucocorticoid therapy on exacerbation of chronic obstructive pulmonary disease. J Gerontology 62: 459-464.

20. Gerardi G, Usberti M, Martini G, Albertini A, Sugherini L, et al (2002) Plasma total antioxidant capacity in hemodialyzed patients and its relationships to other biomarkers of oxidative stress and lipid peroxidation. Clin Chem Lab Med 40:104110 .

21. Ippolito S, Caruso R, Nobembrino C et al (2002) Dislipidemia and oxidative stress. Ital J Biochem 51: 129.

22. Cesarone MR, Belcaro G, Carratelli M, Cornelli U, De Sanctis MT, et al. (1999) A simple test to monitor oxidative stress. Int Angiol 18: 127-130. [crossref]

23. Celi P, Sullivan M, Evans D (2010) The stability of the reactive oxygen metabolites (d-ROMs) and biological antioxidant potential (BAP) tests on stored horse blood. Vet $J$ 183: 217-218.

24. Sharma RK, Pasqualotto FF, Nelson DR, Thomas AJ Jr., Agarwal A (1999) The reactive oxygen species-total antioxidant capacity score is a new measure of oxidative stress to predict male infertility. Hum Reprod 14: 2801-2807.

25. Pedernera M, Celi P, García SC, Salvin HE, Barchia I, and Fulkerson WJ (2010) Effect of diet, energy balance and milk production on oxidative stress in earlylactating dairy cows grazing pasture. Vet $J 186: 352-357$.

26. Celi P (2011) Biomarkers of oxidative stress in ruminant medicine. Immunopharmacol Immunotoxicol 33: 233-240.

27. Komatsu F, Kagawa Y, Kawabata T, Kaneko Y, Ishiguro K (2009) Relationship of dietary habits and obesity to oxidative stress in Palauan people: compared with Japanese and Mongolian people. Curr Aging Sci 2: 214-22.

28. Komatsu F, Kagawa Y, Kawabata T, Kaneko Y, Purvee B, et al (2008) Dietary habits of Mongolian people, and their influence on lifestyle-related diseases and early aging. Curr Aging Sci 2: 84-100.

29. Hirose H, Kawabe H, Komiya N, Saito I (2009) Relations between serum reactive oxygen metabolites (ROMs) and various inflammatory and metabolic parameters in a Japanese population. J Atheroscler Thromb 16: 77-82

30. Kamezaki F, Yamashita K, Kubara T, Suzuki Y, Tanaka S, et al (2008) Derivatives of reactive oxygen metabolites correlates with high-sensitivity C-reactive protein. $J$ Atheroscler Thromb 15: 206-212.

31. Fukui T, Yamauchi K, Maruyama M, Yasuda T, et al (2011) Significance of measuring oxidative stress in lifestyle-related diseases from the viewpoint of correlation between d-ROMs and BAP in Japanese subjects. Hypertens Res 34: 1041-1045.

32. Komatsu F, Kudoh H, Kagawa Y (2007) Evaluation of oxidative stress and effectiveness of low-dose glucocorticoid therapy on exacerbation of chronic obstructive pulmonary disease. J Gerontology 62A: 459-464.

33. Markoulis N, Gourgoulianis KI, Moulas A, Gerogianni E, Molyvdas AP (2006) Reactive oxygen metabolites as an index of chronic obstructive pulmonary disease severity. Panminerva Med 48: 209-213.

34. Suzuki S, Matsukura S, Takeuchi H, Kawaguchi M, Ieki K, et al. (2008) Increase in reactive oxygen metabolite level in acute exacerbations of asthma. Int Arch Allergy Immunol 146: 67-72.

35. Tamaki N, Tomofuji T, Ekuni D, Yamanaka R, Yamamoto T, Morita M (2009) Short-term effects of non-surgical periodontal treatment on plasma level of reactive oxygen metabolites in patients with chronic periodontitis. J Periodontol 80: 901906.
36. Tamaki N, Tomofuji T, Maruyama T, Ekuni D, Yamanaka R, et al (2008) Takeuchi $\mathrm{R}$, Yamamoto $\mathrm{T}$. Relationship between periodontal condition and plasma reactive oxygen metabolites in patients in the maintenance phase of periodontal treatment. J Periodontol 79: 2136-2142.

37. Sakane N, Fujiwara S, Sano Y, Domichi M, Tsuzaki K, et al. (2008) Matsuoka Y, Hamada T, Saiga K, Kotani K. Oxidative stress, inflammation, and atherosclerotic changes in retinal arteries in the Japanese population; Results from the mima study. Endocrine Journal 55: 485-488.

38. Christou K, Markoulis N, Mouslas AN, Pastaka C, Gourgoulianis KI (2003) Reactive oxygen metabolites (ROMs) as an index of oxidative stress in obstructive sleep apnea patients. Sleep and Breathing 7: 105-110.

39. Komatsu F, Kagawa Y, Ishiguro K, Kawabata T, Purvee B, et al (2009) The association of very high hair manganese accumulation and high oxidative stress in Mongolian people. Curr Aging Sci 2: 28-42.

40. Olinski R, Siomek A, Rozalski R, Gackowski D, Foksinski M, et al (2007) Oxidative damage to DNA and antioxidant status in aging and age-related diseases. Acta Biochim Pol 54: 11-26.

41. Halliwell B (2007) Biochemistry of oxidative stress. Biochemical Society Transactions 35: 1147-1150.

42. MartinoviÄ $\ddagger$ J, Dopsaj V, Kotur-StevuljeviÄł J, Dopsaj M, VujoviÄł A, et al. (2011) Oxidative stress biomarker monitoring in elite women volleyball athletes during a 6-week training period. J Strength Cond Res 25: 1360-1367. [crossref]

43. Elosua R, Molina L, Fito M, et al. (2003) Response of oxidative stress biomarkers to a 16-week aerobic physical activity program, and to acute physical activity, in healthy young men and women. Atherosclerosis 167: 327-334.

44. Knez WL, Coombes JS, Jenkins DG (2006) Ultra-endurance exercise and oxidative damage: Implications for cardiovascular health. Sports Med 36: 429-141.

45. Bloomer RJ, Goldfarb AH (2004) Anaerobic exercise and oxidative stress: a review. Can J Appl Physiol 29: 245-263. [crossref]

46. Radak Z, Taylor AW, Ohno H, Goto S (2001) Adaptation to exercise-induced oxidative stress: from muscle to brain. Exerc Immunol Rev 7: 90-107. [crossref]

47. Kamezaki F, Yamashita K, Kubara T, Suzuki Y, Tanaka S, et al. (2008) Derivatives of reactive oxygen metabolites correlates with high-sensitivity C-reactive protein. $J$ Atheroscler Thromb 15: 206-212.

48. Bloomer RJ, Fisher-Wellman KH (2008) Blood oxidative stress biomarkers: influence of sex, exercise training status, and dietary intake. Gend Med 5: 218-228. [crossref]

49. Komatsu F, Kagawa Y, Sakuma M, Kawabata T, Kaneko Y, et al. (2006) Investigation of oxidative stress and dietary habits in Mongolian people, compared to Japanese people. Nutr Metab 7: 3-21.

50. Gil-Agustí M, Esteve-Romero J, Carda-Broch S (2008) Anserine and carnosine determination in meat samples by pure micellar liquid chromatography. $J$ Chromatogr A 1189: 444-450. [crossref]

51. Chan KM, Decker EA (1994) Endogenous skeletal muscle antioxidants. Crit Rev Food Sci Nutr 34: 403-426.

52. Wijeratne SS, Cuppett SL (2007) Soy isoflavones protect the intestine from lipid hydroperoxide mediated oxidative damage. J Agric Food Chem 55: 9811-9816.

53. Erba D, Casiraghi MC, Martinez-Conesa C, Goi G, Massaccesi L (2012) Isoflavone supplementation reduces DNA oxidative damage and increases O- $B-N$-acetyl-Dglucosaminidase activity in healthy women. Nutr Res 32: 233-240.

54. Bazzoli DL, Hill S, DiSilvestro RA (2002) Soy protein antioxidant actions in active, young adult women. Nut Res 7: 807-815.

55. Nielsen F, Mikkelsen BB, Nielsen JB, et al. (1997) Plasma malondialdehyde as biomarker for oxidative stress: Reference interval and effects of life-style factors. Clin Chem 43: 1209-1214.

56. Asami S, Hirano T, Yamaguchi R, et al. (1998) Effects of forced and spontaneous exercise on 8-hydroxydeoxyguanosine levels in rat organs. Biochem Biophys Res Commun 243: 678-682.

57. Ide T, Tsutsui H, Ohashi N, et al. (2002) Greater oxidative stress in healthy young men compared with premenopausal women. Arterioscler Thromb Vasc Biol 22: $438-442$.

58. Wactawski-Wende J, Schisterman EF, Hovey KM, Howards PP, Browne RW, et al. (2009) BioCycle Study Group. BioCycle study: design of the longitudinal study of the oxidative stress and hormone variation during the menstrual cycle. Paediatr Perinat Epidemiol 23: 171-84.

\section{Citation:}

Kazuyoshi Tamae, Kazuhiro Aoki, Shingo Nakamaru, Kazunori Koshikawa, Kazuhiko Sakuma, Takeshi Hirano (2019) The Associations of Reactive Oxygen Metabolites and Biological Antioxidant Potentials with Related Factors in Healthy Youth. Ageing Sci Ment Health Stud Volume 3(3): 1-8. 